\title{
Nursing Now! Movement for the valorization of Nursing and for the strengthening of global health
}

\author{
Ítalo Rodolfo Silva ${ }^{a}$ \\ Isabel Amélia Costa Mendes ${ }^{b}$
}

\section{How to cite this article:}

Silva IR, Mendes IAC. Nursing Now! Movement for the valorization of Nursing and for the strengthening of global health [editorial]. Rev Gaúcha Enferm. 2021;42(spe):e20210053. doi: https://doi.org/10.1590/19831447.2021.20210053 aniversidade Federal do Rio de Janeiro (UFRJ). Rio de Janeiro, Rio de Janeiro, Brasil.

- Universidade de São Paulo (USP). Escola de Enfermagem de Ribeirão Preto. Ribeirão Preto, São Paulo, Brasil.
The world is facing the greatest sanitary crisis in a long time. This reality has required an urgent response from the nations regarding actions to fight the disease that risks everyone's life, not only because of the transmission capacity of the new coronavirus, or the ailment and death of infected people, but also due to the collapse that COVID-19 pandemics might bring onto health systems.

A global diagnostic of contextual specificities has appeared, although informally, from this situation, highlighting to the world the need of greater investments in health care systems. However, such investments need to consider the relevance of those who constitute and have an impact on the functioning dynamics of health care systems. That being said, maybe it is the main lesson that this current pandemic can bestow upon society, but that lesson will not be fulfilled without the due valorization of Nursing.

Now the world needs to understand that nurses represent the greatest part of health human resources. We are almost 28 million professionals worldwide ${ }^{(1)}$, whose relevance is not limited to those figures, but also includes the coverage and quality of the care offered, since we are present in the most varied fields and health care services, and we are still crucial responding to people's health care needs in all their life cycle, that is to say, from even before they are born to the care of the lifeless body and the mourning family.

Nurses'work has direct impact on health promotion and recovery and in the reduction of risks and disease aggravations. Besides, with the pandemics going on, the world echoes the words 'front line', evoking an image of war. However, it is important to say that Nursing is not only present in the health care front line, but it is also based in scientific evidence for the planning of health care services, because from Florence Nightingale this systemic approach to health, care and work has been a part of nurses' identity worldwide. With all that, nurses have an impact not only on the lives of the people we assist, but also on national and global economies.

Government and decision-makers need to understand that no global health agenda will be possible without Nursing. Nations should be aware that without Nursing, health systems will collapse, because although we are many, we are still in a fragile situation in our working processes due to the lack of investments and incentive.

Despite that reality, it has to be considered that we are all within a system that is highly dynamic, whose dimensions of health, economy, social development, life quality, sovereignty and human dignity are all intertwined. In that scenario, the current pandemics reveals only a face of this complex system, since challenges are many and constant for the 
health care field. These challenges involve the natural dynamics of population aging; social inequalities in the perspective of health; emergent, re-emergent and neglected diseases; chronic health conditions, among many other topics. In all those challenging contexts, Nursing is present, but invisible for those who should value it: society —in part due to the lack of awareness of Nursing impacts - and employers, be it the Federal State of private organizations.

Among so many challenges, based on the World Health Organization, the International Council of Nurses and the Burdett Trust For Nursing, global Nursing celebrated the Campaign Nursing Now in 2018, which aims at amplifying the movements and debates that will strategically promote the strengthening of Nursing to reach leadership that can reach decision-making levels and influence the work of the Nurses.

That campaign reached Brazil in April 2019 with an opening ceremony in the country's capital, leaded by the Federal Council of Nursing and the Collaborator Center of PAHO/WHO for the Development of Research in Nursing, at the Nursing School of Ribeirao Preto, University of Sao Paulo. Considering all the complexity of the challenges for the valorization of Nursing, the Campaign Nursing Now Brazil defined three goals regarding the process of education of Nursing professionals with a focus on leadership: decent working conditions and the dissemination of the successful experiences and initiatives of Brazilian Nursing for a greater visibility.

Since then, from the North to the South of this continental Brazil, from East to West, Nursing has organized debates, reflections and valorization proposals that emerge from the present so that we can continue fulfilling our social roles. The campaign began gradually to become the Nursing Now Movement, which brings a feeling of belonging to Nursing and of collective efforts for valorization. In that journey, Nursing needs to be coherent in the internal strengthening, based on forums between pairs, but also, and specially, to expand Nursing's voice (2). We need to reach all the society, from the local dimension to national and global contexts.

In that sense, the dissemination of knowledge based on the scientific production of Nursing is a fine strategy for improving Nursing in the goals of the Nursing Now Campaign. That is why we are celebrating the successful initiative of the journal Revista Gaúcha de Enfermagem in eternalizing a crucial part of Nursing contributions in a historical moment for humanity and for our profession in this special issue.

We hope that the readers from NOW appreciate the articles gathered here to help build knowledge and attitudes to continue changing reality; and that the readers of TOMORROW can receive, as a gift, the record and the care of those that in the past could think, develop and register the contributions of Nursing during COVID-19 pandemics, in the International Year of Nursing (2020), Nursing Now Campaign and the bicentennial of Florence Nightingale (2020) to History.

\section{REFERENCES}

1. World Health Organization (CH). State of the world's nursing 2020: investing in education, jobs and leadership.Geneva: WHO; 2020 [cited 2021 Jan 10 ]. Available from: https://www.who.int/publications/i/item/9789240003279

2. Thorne S. Time to get loud. Nurs Inq. 2021;28:e12400. doi: https://doi.org/10.1111/nin.12400

\section{- Corresponding author:}

Ítalo Rodolfo Silva

E-mail: italoufrj@gmail.com 